\title{
A gestão democrática da educação básica no âmbito do plano de ações articuladas municipal: tensões e tendências
}

NEUSA CHAVES BATISTA Universidade Federal do Rio Grande do Sul, Porto Alegre, RS, Brasil

RESUMO

$\mathrm{O}$ artigo analisa a implementação da política nacional Plano de Ações Articuladas no estado do Rio Grande do Sul. Trata-se de uma política pública, iniciada em 2007, com a finalidade de articular ações educacionais entre a União e os municípios com vistas à melhoria da qualidade do ensino e aprendizagem nas municipalidades. No ordenamento legal, cabe à União a coordenação da política nacional de educação, articulando os diferentes níveis e sistemas; já a gestão democrática da educação é princípio para a autonomia dos sistemas municipais de ensino. $\mathrm{Na}$ análise identificam-se as tensões na relação entre União e municípios com base no exame das situações e tendências dos indicadores da área gestão democrática e desenvolvimento dos sistemas de ensino. $\mathrm{O}$ estudo aponta que as ações e subações planejadas para essa área entre municípios (secretarias municipais de educação) e União (Ministério da Educação) ainda são frágeis no que tange ao seu cumprimento por ambas às partes comprometidas.

PALAVRAS-CHAVE

gestão democrática; política PAR; educação municipal. 


\title{
DEMOCRATIC MANAGEMENT OF BASIC EDUCATION IN THE MUNICIPAL ARTICULATED ACTIONS PLAN: TENSIONS AND TENDENCIES
}

\begin{abstract}
This study analyzes the implementation of the National Policy of Articulated Action Plans in the state of Rio Grande do Sul. It is a public policy that began in 2007 with the objective of articulating educational activities between the Union and the municipalities in order to improve the quality of teaching and learning in the municipalities. According to the legal system, the coordination of the national policy of education is a Union's responsibility, articulating the different levels and systems, while the democratic management of education is the foundation for the autonomy of municipal education systems. In this study, we identified the tensions in the relationship between the Union and municipalities by analyzing the situations and tendencies of the indicators in the field of democratic management and development of teaching systems. The study shows that the actions and subactions planned for this field between municipalities (Municipal Departments of Education) and the Estate (Ministry of Education) are still fragile in terms of their fulfillment by both the engaged parties.
\end{abstract}

KEYWORDS

democratic management; PAR policy; municipal education.

\section{LA GESTIÓN DEMOCRÁTICA DE LA EDUCACIÓN BÁSICA EN EL MARCO DEL PLAN DE ACCIONES ARTICULADAS MUNICIPAL: TENSIONES Y TENDENCIAS}

RESUMEN

En este artículo se analiza la implementación de la política nacional Plan de Acciones Articuladas en el estado de Rio Grande do Sul. Se trata de una política pública, iniciada en 2007, con la finalidad de articular acciones educacionales entre la Unión y los municipios y que tiene el objetivo de mejorar la calidad de la enseñanza y del aprendizaje en las municipalidades. En el ordenamiento jurídico, cabe a la Unión la coordinación de la política nacional de educación, que articula los diferentes niveles y sistemas; ya la gestión democrática de la educación es principio para la autonomía de los sistemas municipales de enseñanza. En el análisis se identificaron las tensiones en la relación entre Unión y municipios, a partir del examen de las situaciones y tendencias de los indicadores del área de gestión democrática y desarrollo de los sistemas de enseñanza. El estudio señala que las acciones y sub acciones planificadas para este área entre Municipios (Secretarías municipales de Educación) y Unión (Ministerio de Educación) todavía son frágiles en lo que atañe a su cumplimiento por ambas partes comprometidas.

PALABRAS CLAVE

gestión democrática; política PAR; educación municipal. 


\section{INTRODUÇÃO}

No Brasil, a década de 1980, no que diz respeito à organização da sociedade civil na busca dos direitos de cidadania, foi pródiga em protagonismo na construção de novos marcos legais para a educação pública. Ampliou-se o direito à educação de modo que se pudesse dar suporte para um ensino que garantisse o acesso, a permanência e a qualidade para todos os educandos. Nesse contexto, incorpora-se ao texto constitucional o princípio de gestão democrática do ensino público, bem como se afere aos municípios maior grau de autonomia para a gestão da educação municipal (Batista, 2013).

$\mathrm{Na}$ esteira desses acontecimentos, a organização do sistema educacional brasileiro, cujas bases federativas republicanas sempre implicaram responsabilidades aos entes subnacionais, passa por um processo de reorganização em virtude do reconhecimento dos municípios como entes federados autônomos na Constituição Federal de 1988 (Brasil, 1988), conferindo autonomia política às municipalidades no que tange à concepção e gestão de políticas sociais, impulsionando ações efetivas de descentralização político-administrativas. Desse modo, a Constituição Federal de 1988 e a Lei de Diretrizes e Bases da Educação Nacional (LDBEN) n. 9.394, de 20 de dezembro de 1996 (Brasil, 1988, 1996), ao definirem as competências e atribuições dos entes federados (União, Estados, Distrito Federal e municípios), estabelecem com clareza a autonomia dos municípios para criar e gerir o seu próprio sistema de ensino em oferta, organização e gestão da educação municipal.

O mesmo ordenamento legal, ao referenciar sobre as competências e atribuições dos entes federados no que diz respeito à organização da educação nacional, estabelece que a União, os estados, o Distrito Federal e os municípios organizarão, em regime de colaboração, os respectivos sistemas de ensino. $\mathrm{O}$ artigo $8^{\circ}$, em seu $\S 1^{\circ}$ da LDBEN, estabelece que cabe à União a coordenação da política nacional de educação, articulando os diferentes níveis e sistemas e exercendo função normativa, redistributiva e supletiva em relação às demais instâncias educacionais. Já o artigo 11 afirma que cabe aos municípios organizar, manter e desenvolver os órgãos e instituições oficiais dos seus sistemas de ensino, integrando-os às políticas e planos educacionais da União e dos estados.

Como decorrência das atribuições da União com a educação básica (Brasil, 1996), o Ministério da Educação (MEC), a partir de 2007, induz a política nacional Plano de Ações Articuladas (PAR), cujo objetivo central tem sido levar aos municípios programas de assistência técnica e financeira voluntários, ${ }^{1}$ por meio da realização de diagnóstico da situação educacional do município e daí o planejamento de ações articuladas entre o MEC e os municípios, tendo em vista uma intervenção

1 Existe um conjunto de programas do MEC — por exemplo: Programa Nacional de Alimentação do Escolar (PNAE), Programa Dinheiro Direto na Escola (PDDE), Programa Nacional de Transporte Escolar (PNTE) - que pode ser chamado de universal por atingir todas as escolas ou redes do Brasil, previsto em lei ou medida provisória. Todos os outros programas que não são obrigatórios por força da norma legal são chamados de assistência técnica e financeira voluntária. 
direta e planejada nos problemas identificados. Entre as dimensões educacionais abordadas pelo PAR está a da gestão educacional; nessa dimensão encontra-se a área da gestão democrática: articulação e desenvolvimento dos sistemas de ensino. Essa área do PAR apresenta uma relação direta entre gestão democrática e desenvolvimento dos sistemas de ensino no âmbito municipal.

O objetivo central deste artigo é o de explicitar as principais tensões na relação entre as políticas educacionais induzidas pela União (MEC) aos municípios por meio da política educacional PAR e mais especificamente no que diz respeito à gestão democrática dos sistemas de ensino como princípio do exercício da autonomia municipal.

A fim de dar substância empírica ao objetivo destacado, analisam-se as situações e as tendências dos seguintes indicadores de gestão democrática no PAR de 38 municípios do Rio Grande do Sul: conselhos escolares; conselho municipal de educação; projeto pedagógico; critérios para a escolha da direção escolar; plano municipal de educação. As fontes utilizadas para a análise constituem-se de: banco de dados sobre o PAR de 38 municípios do Rio Grande do Sul constituído pelo Núcleo de Estudos de Políticas e Gestão da Educação da Universidade Federal do Rio Grande do Sul (NEPGE/UFRGS), ${ }^{2}$ bem como documentos oficiais da política PAR. O banco de dados foi composto de informações retiradas do monitoramento das ações do PAR de 38 municípios, pela equipe de pesquisadores/as do referido núcleo. Entre 2009 e 2010, foram monitoradas as ações e as subações planejadas no PAR de 143 municípios priorizados pelo MEC no Rio Grande do Sul; contudo, somente 38 municípios assinaram o Termo de Consentimento Informado para o uso de dados em pesquisas acadêmicas, constituindo-se esse número de municípios em uma amostra por acessibilidade. ${ }^{3}$

Os dados fornecidos ofereciam informações sobre:

- indicador;

- ação/subação;

- forma de execução (MEC ou município);

- estado da subação (não iniciada — em andamento — concluída — suspensa);

- justificativa (do município para o estado da ação/subação);

- limite à execução da ação/subação (do município).

2 Em 2007, o MEC firma convênio com a UFRGS por meio do NEPGE para assistência técnica, incluindo o monitoramento do PAR em 2009-2010, com a implementação do PAR nos municípios prioritários (selecionados pelo MEC) do Rio Grande do Sul, Santa Catarina, Alagoas e Paraíba. Participaram desse processo pesquisadores-professores do núcleo bem como acadêmicos de pós-graduação na área de políticas e gestão da educação (Farenzena, 2012).

3 Esse tipo de amostragem se estabelece quando os pesquisadores possuem conhecimento suficiente do universo a ser pesquisado para admitir que a amostra selecionada pode, de alguma maneira, representar o universo. A amostragem por acessibilidade é destituída dos rigores da amostragem estatística. O pesquisador/a seleciona os elementos a que tem acesso, admitindo que estes possam representar o universo (Gil, 1994). 
Com esses dados tabulados, foi possível idenficar alguns efeitos da política nacional PAR sobre municípios do Rio Grande do Sul, no caso deste artigo, relativamente à área da gestão democrática: articulação e desenvolvimento dos sistemas de ensino.

A abordagem metodológica parte do princípio de que a política pública é um ciclo constituído por contextos inter-relacionados. Vejamos:

- O contexto da influência, no qual normalmente as políticas públicas são iniciadas e os discursos políticos são construídos, apresentando grupos de interesse que disputam para influenciar a definição das finalidades sociais da educação do que significa ser educado; nele os conceitos adquirem legitimidade e formam um discurso de base política.

- O contexto da produção do texto normalmente está articulado com a linguagem do interesse público mais geral, no qual os textos da política representam a política. Esses textos podem não ser coerentes e claros e apresentarem contradições; sua leitura deve considerar o tempo e o local específico de sua produção. Eles são o resultado de disputas e acordos, pois os grupos que atuam dentro dos diferentes lugares da produção de textos competem para controlar as representações da política.

- O contexto da prática, no qual a política está sujeita à interpretação e (re)criação produzindo efeitos e consequências que podem representar mudanças e transformações significativas na política original.

O ponto-chave é que as políticas não são simplesmente "implementadas" dentro dessa arena, mas estão sujeitas à interpretação e então a serem "recriadas". Políticas serão interpretadas diferentemente, uma vez que histórias, experiências, valores, propósitos e interesses são diversos. Assim, a interpretação da política é uma questão de disputa (Ball, 1994; Bowe, Ball e Gold, 1992).

A organização textual que se segue apresenta uma discussão cujo foco está centrado na relação entre gestão democrática da educação e autonomia dos sistemas municipais de ensino. Na seção seguinte destacam-se os aspectos históricos da construção sociopolítica das municipalidades brasileiras bem como conjunturais da reforma do Estado brasileiro e sua implicação com o cumprimento de uma agenda global para as políticas públicas sociais. $\mathrm{Na}$ terceira seção apresenta-se a política nacional PAR, suas principais características e o ordenamento legal que a regula. A quarta seção procede à análise dos indicadores de gestão democrática de 38 municípios do Rio Grande do Sul. Finalmente, na última seção, as considerações finais, empreende-se destacar as principais tensões do texto, dando-lhes tratamento analítico conclusivo.

\section{GESTÃO DEMOCRÁTICA DA EDUCAÇÃO E AUTONOMIA DOS SISTEMAS MUNICIPAIS DE ENSINO: QUAL É A RELAÇÃO?}

Nos anos de 1990, o Brasil insere-se no contexto mundial de reestruturação dos Estados nacionais com vistas a uma readequação ao modelo normativo global 
baseado nos princípios de descentralização, privatização e flexibilização ${ }^{4}$ (Afonso, 2001; Ball, 2013; Borges, 2000). Sob as circunstâncias e determinações dos paradigmas das organizações internacionais, conecta-se à mundialização de uma nova agenda global - "pós-moderna" - sofrendo suas consequências sem nem sequer ter implementado plenamente a agenda "moderna" (Nogueira, 2004). Tal procedimento produz efeitos na organização e estrutura da gestão pública, bem como na implementação de políticas públicas de corte social. Imerso no novo ordenamento para as sociedades capitalistas, o Estado nacional brasileiro, atendendo à solicitação de ajuste estrutural das contas públicas, dá início à modificação da forma de atendimento às demandas sociais adotando como uma de suas estratégias a "descentralização" da gestão e execução de políticas sociais para a esfera municipal.

Com efeito, no contexto sociopolítico da sociedade brasileira, que se encontrava ainda em processo de redemocratização, a gestão democrática da educação, incorporada como demanda dos movimentos sociais da década de 1980 e materializada na Constituição Federal de 1988 (Brasil, 1988), necessita, sob os auspícios do novo ordenamento global para a gestão pública, mobilização social constante para se fazer efetiva na organização e nas práticas dos sistemas de ensino, ${ }^{5}$ assim como das escolas.

$\mathrm{Na}$ década de 1990 o sentido dado pelo modelo normativo global para a gestão pública passa a concorrer com os significados dados pelas sociedades locais (Azevedo, 2001); a reforma do Estado brasileiro, ${ }^{6}$ em meados da década de 1990, incorpora a descentralização da administração pública com vistas a maior eficiência da máquina estatal, adotando medidas de privatização da gestão de políticas sociais, de deslocamento de responsabilidades (flexibilização) entre os entes federados e entre o Estado e a sociedade (Abruscio, 2006; Nogueira, 2004). Tais concepções contrastam com a descentralização da educação como estratégia para a efetivação da gestão democrática da educação vinculada pelos movimentos sociais à participação dos municípios na construção da democracia local como forma de fortalecimento de sua autonomia em relação ao poder central. Nessa última perspectiva a participação

4 Trata-se de uma agenda global cujas diretrizes são claramente defendidas por organismos internacionais, tais como o Fundo Monetário Internacional (FMI), o Banco Mundial e a Organização das Nações Unidas para a Educação, a Ciência e a Cultura (UNESCO) (Borges, 2000; Nogueira, 2004).

5 Conforme Saviani (1999), o sistema resulta da atividade sistematizada; e a ação sistematizada é aquela que busca intencionalmente realizar determinadas finalidades por meio de uma ação planejada, logo, o sistema de ensino é uma ordenação articulada dos vários elementos necessários à consecução dos objetivos educacionais preconizados à população a qual se destina supondo o planejamento de ações.

6 Em 1995, sob a gestão do presidente Fernando Henrique Cardoso, cria-se o Ministério da Administração e Reforma do Estado (MARE), que incorpora as recomendações eos pressupostos de organismos econômicos internacionais: redução de custos e racionalização do gasto público; melhoria da eficiência do aparelho do Estado; descentralização e retirada da responsabilidade do Estado das atividades que possam ser desenvolvidas pelo terceiro setor (Abruscio, 2006). Nas gestões do Partido dos Trabalhadores (PT), esse ministério é extinto, contudo as recomendações dos organismos internacionais permanecem. 
social na esfera municipal é vista como uma estratégia de controle da sociedade local sobre a formulação, implementação e avaliação das políticas educacionais rompendo com a diretividade do poder central (em oposição, especialmente, ao regime militar iniciado em 1964), bem como com práticas políticas autoritárias e patrimonialistas locais.

Dessa forma, os sentidos que são dados tanto para o papel dos municípios perante o modelo federativo ${ }^{7}$ brasileiro de organização social e política quanto à gestão democrática da educação como princípio orientador dos sistemas de ensino necessitam de contextualização. De fato não se pode associar de imediato a autonomia dos municípios com a gestão democrática dos sistemas municipais de ensino, bem como a descentralização com a democratização ou, ainda, a centralização da educação ao autoritarismo. ${ }^{8}$ Segundo Locatelli (2011, p. 4):

[...] centralização e descentralização dos sistemas políticos administrativos constituem na história da organização estatal brasileira dois polos que se interligam numa totalidade, buscando manter os pressupostos básicos para a sustentação da dominação capitalista e da fração burguesa hegemônica. A exclusividade de um polo ou outro não caracteriza a organização do Estado moderno, ou seja, a organização do Estado moderno capitalista não deve ser definitivamente centralizada ou descentralizada já que a mobilidade na prática de governo se torna um recurso de "governabilidade".

A descentralização colocada em curso na pós-reforma do Estado brasileiro, em 1995, mesmo que apoiada pelo modelo federativo de organização social com base na autonomia dos entes federados (União, Distrito Federal, estados e municípios), está calcada na agenda global cuja meta tem sido a desconcentração do poder central, isto é, da gestão e do aparato administrativo, com o objetivo de diminuir os gastos da máquina pública, em especial com as políticas sociais. Fruto dessa agenda global, que incorpora à ação pública novos atores, alguns analistas (Afonso, 2001, 2013) consideram que está em vigor um novo modelo de regulação social chamado "Estado Avaliador". Nessa perspectiva, os Estados nacionais,

[...] independentemente de suas orientações político-ideológicas e, em grande medida, acima delas, participam ou interferem ativamente de formas diversas, na construção de um sistema de indicadores e de avaliação comparada interna-

7 Nos estados federativos, diferentes níveis de governo possuem autoridade sobre a mesma população e território. O governo central, assim como os subnacionais, são independentes entre si, são atores políticos dotados de autonomia e com poder para formular e implementar as políticas municipais (Arretche, 2002).

8 Mesmo que se possa associar, no caso do Brasil, o centralismo da educação a regimes autoritários, especialmente o pós 1964, sob o regime militar. Essas administrações caracterizaram-se por uma excessiva centralização em nível federal das tomadas de decisão sobre os mais variados setores na gestão do país. Isso reforçou movimentos cujas demandas de cunho descentralizador se contrapunham ao período autoritário e centralizador (Castro e Duarte, 2008). 
cional em larga escala cujas consequências, mais imediatas, permitem legitimar muitos discursos e vincular muitas políticas nacionais para a educação e formação. (Afonso, 2013, p. 274)

Além disso, as municipalidades brasileiras guardam especificidades históricas em sua formação sociopolítica que trazem marcas, até a atualidade, em seu modo de gerir o bem público. O regime federativo ao qual o Brasil está vinculado é do tipo cooperativo, especialmente a partir da Constituição de 1988, no qual existem formas de ação conjunta entre esferas de governo e as unidades subnacionais detêm significativa autonomia decisória e capacidade de autofinanciamento (Luce e Farenzena, 2008). Essa relação pressupõe o regime democrático como norte para a autonomia do poder local e a descentralização.

No entanto, as representações históricas do poder político no Brasil estão vinculadas, mesmo sob um Estado moderno impessoal e racional legal, a práticas políticas de cunho patrimonialistas, coronelistas e clientelistas, as quais têm reproduzido no âmbito dos municípios governos centralizados e autoritários. O clientelismo é uma prática política presente na sociedade brasileira desde os tempos coloniais. Consolida-se pela via da troca de favores entre detentores do poder político e alguns "eleitores" por meio de relações herdadas do Estado patrimonialista cuja maior característica é a não diferenciação entre bem público e bem privado. Já o coronelismo, como prática histórica do processo político brasileiro, caminhou com o regionalismo; o coronel legitimava o seu poder e dominação em regiões específicas, regulando nas três esferas de poder da federação. Era figura tradicional na localidade, dominando a todos pelo carisma, poderio econômico, técnico e intelectual, mas também pelo medo, já que detinha influência sobre a força policial, fosse ela pública ou privada. Era comum, ao coronel, recorrer à violência política para intimidar ou manipular a população (Félix, 1987). Essas práticas ainda são latentes nos municípios brasileiros até os dias de hoje.

Diante do quadro exposto nesta seção, recoloca-se a tensão salientada na introdução sobre a indução de políticas educacionais nacionais, como é o caso do $\mathrm{PAR}$, para os municípios brasileiros, ainda mais quando essa política traz dimensões que propõem a gestão democrática como base para o desenvolvimento dos sistemas municipais de ensino.

\section{A POLÍTICA NACIONAL PLANO DE AÇÕES ARTICULADAS (PAR)}

Em abril de 2007, no intuito de colocar em prática sua principal ação para o setor da educação, o MEC divulga as linhas gerais do Plano de Desenvolvimento da Educação (PDE) com um conjunto de estratégias e atos normativos para a implementação de ações articuladas entre a União, o Distrito Federal, os estados e os municípios. A proposta inicial do MEC fundamentava-se no Plano de Metas Compromisso Todos pela Educação como uma das principais diretrizes do PDE. Para colocar em prática o plano de metas, vinculado a este cria-se o PAR como um instrumento de planejamento educacional que proporcionaria aos estados e municípios, por meio de um diagnóstico da situação educacional e daí o planejamento 
de ações articuladas entre a União e os entes subnacionais, o acesso a programas de transferência voluntária do MEC. Para tal, os municípios e os estados deveriam assinar um termo de "adesão" ao compromisso Todos pela Educação. Até o final de 2008, todos os 5.563 municípios brasileiros já haviam aderido ao Plano de Metas (Farenzena, 2012). Em 25 de julho de 2012, por meio da lei n. 12.695 (Brasil, 2012), que dispõe sobre apoio técnico ou financeiro da União no âmbito do Plano de Ações Articuladas (Brasil, 2012), o PAR assume status de política nacional desvinculando seus objetivos do plano de metas e vinculando-se ao Plano Nacional de Educação (PNE).

Para a abordagem a respeito da política nacional PAR, parte-se do pressuposto de que a compreensão dos resultados das políticas públicas está além das decisões de Estado; trata-se, pois, de se interrogar sobre o próprio funcionamento da democracia em sociedades capitalistas consideradas em sua diversidade socioeconômica, política e cultural. Isso implica entender a política pública como um constructo social e local (Müller e Surel, 2002). Com base na assertiva, pode-se dizer que a política pública é um ciclo que se ressignifica conforme os contextos, sempre inter-relacionados, que apresentam arenas, lugares e grupos de interesses, cada um envolvendo disputas e embates (Ball, 1994; Bowe; Ball; Gold,1992).

Se for considerada a partir de sua recepção no contexto dos municípios, a implementação do PAR nos municípios brasileiros, mesmo que induzida pelo MEC, pode sofrer efeitos não previstos nos objetivos e estimativa de resultados da política original - no caso, formulada pelo MEC. As políticas públicas quando são implementadas sofrem múltiplas influências, disputas e embates no contexto da prática. Assim, os próprios municípios no exercício de sua autonomia podem atribuir novos sentidos para os objetivos da política nacional criando-lhe um novo ciclo, ressignificando a política.

O PAR, em sua origem, nasce vinculado ao Plano de Metas Compromisso Todos pela Educação, que supunha a adesão voluntária dos estados e municípios. Com suas linhas gerais dadas pelo decreto n. 6.094, de 24 de abril de 2007, foi pautado em vinte e oito diretrizes visando à melhoria da qualidade da educação básica no Brasil (Brasil, 2007c). Para realizar o monitoramento da evolução da qualidade do ensino, criou-se um indicador objetivo chamado Índice de Desenvolvimento da Educação Básica (IDEB). Esse indicador permite o monitoramento da evolução da situação educacional, compreendendo metas intermediárias (a cada dois anos) e finais (até 2022). ${ }^{9}$ Segundo o artigo $3^{\circ}$ do decreto $n, 6.094 / 2007$, o IDEB deve ser obtido a partir dos dados sobre rendimento escolar, combinados com o desempenho dos alunos, constantes do

9 A média nacional do IDEB em 2005 foi de 3,8 nos primeiros anos do ensino fundamental. Em 2007, essa média subiu para 4,2. A meta é atingir até 2022 a média 6,0. A fixação da média 6,0 a ser alcançada considerou o resultado obtido pelos países da Organização para a Cooperação e Desenvolvimento Econômico (OCDE). A nota 6,0 foi a média obtida pelos países desenvolvidos que ficam entre os vinte mais bem colocados no mundo (Brasil, 2007a). 
censo escolar e do Sistema de Avaliação da Educação Básica (SAEB), composto pela Avaliação Nacional da Educação Básica (ANEB) e a Avaliação Nacional do Rendimento Escolar (ANRESC), também conhecido como Prova Brasil. Entre os 5.563 municípios brasileiros, aqueles com o IDEB mais baixo (menos de 3,8) receberam assistência técnica do MEC para a elaboração do PAR: no que diz respeito ao acesso a programas do $\mathrm{MEC}$, a política prevê que tenham prioridade os municípios de mais baixo IDEB.

Essa "febre avaliativa" da educação presente na política PAR e levada aos municípios reflete a agenda global incorporada pelo Brasil na década de 1990, cujas ações do Estado são compreendidas para imprimir maior racionalidade aos processos de gestão educacional, na qual a qualidade do ensino é medida por indicadores quantitativos. Busca-se obter melhor desempenho escolar no que concerne à aquisição de competências e habilidades relacionadas ao trabalho, controles mais diretos sobre os conteúdos curriculares e sua avaliação (Azevedo, 2004; Ball, 2010; Coelho, 2008). Com essa base, a política PAR não foge à marca da regulação e da administração gerencial e competitiva. Segundo interpreta Afonso (2013, p. 271), a emergência do "Estado avaliador" pode ser percebida pela radicalização da interferência e controle do Estado por meio de avaliação sistêmica.

O PAR, em seu desenho inicial, focalizou os municípios brasileiros com baixo IDEB (abaixo de 3,8), considerando prioritários 1.240 municípios para receberem, até o final de julho de 2008, a assistência técnica do MEC para a sua elaboração em dois momentos inter-relacionados: no primeiro, elabora-se o diagnóstico da situação educacional da rede municipal de ensino e, no caso do estado, da rede estadual de ensino; e, em um segundo momento, com base no diagnóstico, planejam-se as ações para quatro anos (em colaboração entre estados, municípios e União). A orientação do MEC foi a de que o PAR, nos municípios prioritários, fosse elaborado por uma equipe local com representação de segmentos do governo, da comunidade escolar e local e com o apoio técnico de consultores do MEC. ${ }^{10}$ As dimensões educacionais integrantes do PAR são:

1. gestão educacional;

2. formação de professores e dos profissionais de serviço e apoio escolar;

3. práticas pedagógicas e avaliação;

4. infraestrutura física e recursos pedagógicos (Brasil, 2007b).

As condições dadas para a elaboração do PAR nos municípios prioritários, mesmo que tenham interferido na organização local, produziram efeitos de autoavaliação e ressignificação da política. No processo, as dimensões, áreas e indicadores educacionais, elaborados pelo MEC e organizados no Sistema Integrado de Monitoramento, Execução e Controle do Ministério da Educa-

10 A pesquisadora atuou como consultora da política PAR em municípios do Rio Grande do Sul e Santa Catarina. Tal participação se deu com base em convênio entre o MEC e a UFRGS por meio do NEPGE. 
ção (SIMEC) para acesso dos municípios com senha própria, ${ }^{11}$ são abordadas e avaliadas pela equipe local. Nesse momento do contexto da prática da política, os atores locais entram em cena interpretando-a com base me elementos sociopolíticos, econômicos e culturais locais. Tal interferência do local na política nacional pode ser percebida no próprio contexto do texto da política, que vai sofrendo modificações ao longo da implementação do PAR nos municípios brasileiros. No ciclo da política, o local modificou o nacional ao incluir novas demandas (indicadores) no texto da política original. Na primeira etapa do PAR (2007-2011), existiam 52 indicadores, já na segunda etapa (2011-2014) foram excluídos indicadores que não faziam sentido para os municípios e acrescentados outros, chegando a 82 indicadores para serem divididos entre dimensões e áreas. Muitos desses novos indicadores atendem a solicitações dos municípios com vistas à adequação do conteúdo da política às necessidades do sistema de ensino municipal (Brasil, 2007a, 2007b, 2011).

Assim, pode-se dizer que no início da implementação do PAR, dadas as prioridades traçadas pelo MEC no plano de metas - tanto de assistência técnica para elaboração do PAR quanto de atendimentos às ações planejadas -, a política atingiu com maior intensidade os municípios considerados prioritários. No entanto, em 2009, praticamente todos os municípios brasileiros elaboraram ou estavam elaborando o seu PAR com vistas a acessar os programas não universalizados e oferecidos voluntariamente pelo MEC (Farenzena, 2012).

No ano de 2012, por meio da lei n. 12.965/2012 (Brasil, 2012), ocorre uma repactuação em relação ao apoio técnico ou financeiro prestado pela União em caráter suplementar ou voluntário para as redes públicas dos entes subnacionais, na qual o PAR adquire status de política nacional ao vincular suas metas ao PNE, conforme indicado anteriormente. Com a lei 12.965/2012, dissolve-se o Comitê Nacional Compromisso Todos pela Educação, instituído no escopo do plano de metas e com atribuições restritas à mobilização social em prol da qualidade da educação básica, e cria-se no âmbito do MEC o Comitê Estratégico do PAR com atribuições de definição, monitoramento e revisão das ações de assistência da União incorporando a representação de atores diretamente relacionados com a implementação da política no âmbito local, respectivamente, a União Nacional dos Dirigentes Municipais de Educação (UNDIME) e o Conselho Nacional de Secretários Estaduais de Educação (CONSED). Com isso, percebe-se o raio de ação dessa política.

\section{O PAR E A GESTÃO DEMOCRÁTICA DOS SISTEMAS MUNICIPAIS DE ENSINO: PONTUANDO ACHADOS NO RIO GRANDE DO SUL}

No Rio Grande do Sul a adesão inicial dos municípios à política nacional PAR foi delimitada, entre outros fatores, pela indicação do MEC de 142 municípios

11 Os instrumentos que compõem o PAR ("instrumento de campo" para a realização do diagnóstico, assim como o "guia prático de ações" para o planejamento) são elaborados pelo MEC e acessados online pelos municípios e estados via SIMEC (Brasil, 2007a, 2007b). 
que apresentavam IDEB abaixo de 3,8 e que deveriam receber assistência técnica para a elaboração do PAR. Os municípios selecionados foram divididos inicialmente em duas categorias: os prioritários e os preferenciais. Os prioritários, em número de 24 e com IDEB abaixo de 3, estavam elencados na resolução CD/FNDE n. 29, de 20 de junho de 2007 (Brasil, 2007d) e deveriam ser atendidos com a máxima urgência, ou seja, ainda em 2007; já os preferenciais, em número de 118, deveriam ser atendidos até julho de 2008. Em 2009, os 142 municípios selecionados passaram a ser chamados de prioritários.

A coordenação da política no Rio Grande do Sul foi realizada, até 2013, pelo NEPGE/UFRGS, por meio da gestão financeira e administrativa do trabalho que envolvia inicialmente os municípios prioritários e preferenciais que assinaram o termo de compromisso. $\mathrm{O}$ trabalho incluiu desde a constituição de uma equipe técnica para atuar na consultoria com os municípios na elaboração do PAR até uma coordenação centralizada no NEPGE fazendo articulações (contatos e agendamentos) com os municípios, com o MEC e o Fundo Nacional de Desenvolvimento da Educação (FNDE). A mesma coordenação e equipe que atuaram no apoio à elaboração do PAR nos municípios a partir de 2007 também atuaram no monitoramento das ações do PAR, em 2009-2010, nos 142 municípios prioritários. Paralelamente a esse trabalho, os pesquisadores/as do NEPGE realizaram/ realizam pesquisas acadêmicas ${ }^{12}$ sobre a política constituindo um banco de dados valendo-se de 38 municípios prioritários que fizeram o monitoramento das ações e subações planejadas e que assinaram o Termo de Consentimento Informado, fornecendo dados.

O estudo a seguir é fruto de pesquisa iniciada em 2010, no âmbito do PAR dos 38 municípios prioritários que forneceram dados referentes ao período de 2007-2011. Na análise, dá-se ênfase à dimensão da gestão educacional focando especialmente as situações e tendências dos indicadores da área de gestão democrática: articulação e desenvolvimento dos sistemas de ensino. Os indicadores analisados são os seguintes:

- existência de conselho escolar;

- existência, composição e atuação do Conselho Municipal de Educação;

- existência de projeto pedagógico nas escolas e grau de participação dos professores e do conselho escolar em sua elaboração;

- existência, acompanhamento e avaliação do plano municipal de educação;

- critérios para a escolha da função de diretor/a de escola.

Na pesquisa, procura-se responder como e em que medida a política nacional PAR pode promover a construção de espaços e instrumentos de gestão democrática na esfera municipal.

12 As pesquisas acadêmicas realizadas no estado do Rio Grande do Sul sobre a implementação do PAR nos municípios podem ser vistas em Souza e Batista (2016). 
É importante salientar que a primeira etapa da elaboração do PAR é a realização do diagnóstico da situação educacional no município para localizar as situações problemáticas, assim como as positivas, e daí planejar ações de intervenção na situação negativa identificada. Isto é, diferentemente do que propunham os organismos internacionais, premiar as melhores e oportunizar a competição entre as escolas, por meio do PAR propunha-se ofertar recursos para que as escolas em situações precárias se fortalecessem para alterar essa situação. Para realizar o diagnóstico, a equipe local pontuava os indicadores a partir de suas dimensões e áreas.

O Quadro 1, com base no "instrumento de campo" (Brasil, 2007a) elaborado para a realização do diagnóstico (2007-2011), apresenta essa pontuação.

A partir das pontuações dadas pela equipe local, constituía-se o planejamento das ações por meio de outro instrumento, o "guia prático de ações" (Brasil, 2007b). Esse guia trazia, respectivamente, dimensões, áreas e indicadores da educação básica. Para cada indicador havia uma ação de intervenção com subações planejadas que poderiam ser de execução do município ou do MEC (assistência técnica e/ ou financeira). A ação previa que as subações fossem articuladas. Desse modo, se um dos entes não cumprisse sua parte da ação e isso permanece assim, no PAR de 2011-2014 ela não se concretizava.

No PAR de 2007-2011, somente os critérios de pontuação 1 e 2 geravam ações com subações planejadas com previsão de assistência do MEC, levando muitos municípios a optarem por pontuações que muitas vezes não correspondiam à real situação educacional do município. A escolha dava-se em virtude de trazer o máximo de recursos possíveis do MEC, o que induzia a equipe local a depreciar muitos dos indicadores avaliados para que os municípios fossem pontuados dentro dos critérios 1 e 2 (Batista et al., 2012). No PAR 2011-2014, esse critério já não existe. Os municípios podem selecionar as subações mesmo que tenham indicado situação positiva para o indicador (Brasil, 2011). Isso indica que, muito

Quadro 1 - Critérios para avaliação da situação educacional dos municípios

\begin{tabular}{|l|l|}
\hline Critérios & \multicolumn{1}{c|}{ Situação da Educação Municipal } \\
\hline Pontuação 1 & $\begin{array}{l}\text { A descrição aponta para uma situação crítica, de forma que não existem aspectos } \\
\text { positivos, apenas negativos ou inexistentes. Serão necessárias ações imediatas, e estas } \\
\text { poderão contar com apoio técnico e/ou financeiro do Ministério da Educação. }\end{array}$ \\
\hline Pontuação 2 & $\begin{array}{l}\text { A descrição aponta para uma situação insuficiente, com mais aspectos } \\
\text { negativos que positivos; serão necessárias ações imediatas, e estas poderão } \\
\text { contar com apoio técnico e/ou financeiro do Ministério da Educação. }\end{array}$ \\
\hline Pontuação 3 & $\begin{array}{l}\text { A descrição aponta para uma situação satisfatória, com mais } \\
\text { aspectos positivos que negativos, ou seja, o município desenvolve, } \\
\text { parcialmente, ações que favorecem o desempenho do indicador. }\end{array}$ \\
\hline Pontuação 4 & $\begin{array}{l}\text { A descrição aponta para uma situação positiva, ou seja, para } \\
\text { aquele indicador não serão necessárias ações imediatas. }\end{array}$ \\
\hline
\end{tabular}

Fonte: baseado em Brasil (2007a).

Elaboração da autora. 
provavelmente, o próprio MEC percebeu que os municípios poderiam apontar uma situação irreal de precarização da situação educacional para então receber assistência técnica e financeira.

Essa análise do diagnóstico da situação educacional dos 38 municípios prioritários da área da gestão democrática: articulação e desenvolvimento dos sistemas de ensino relaciona-se à escolha de indicadores pela equipe local. A tabulação no Quadro 2 indica a escolha de indicadores pelos municípios.

O indicador "conselho escolar" desponta no Quadro 2 como o de maior pontuação, com critérios 1 e 2 para os 38 municípios prioritários (90\%), assinalando uma situação crítica ou insuficiente que necessita de intervenção articulada. O conselho escolar, conforme indica a LDBEN n. 9.394/1996 em seu artigo 14 (Brasil, 1996), é instrumento e espaço de gestão democrática na e da escola; contudo, o município, considerado em sua autonomia como ente federado, deve organizar o processo de sua implantação. O dado aponta que no período de 2007-2011 a maior parte dos 38 municípios prioritários ainda não havia implantado conselhos escolares nas escolas ou mesmo os que possuíam conselhos apresentavam situação insuficiente para seu efetivo funcionamento.

Remetendo às ações e subações previstas para a intervenção no indicador, é possível identificar no texto da política "guia prático de ações"(Brasil, 2007b) uma interferência ou indução do MEC na organização do sistema municipal de ensino

Quadro 2 - Escolhas de indicadores do PAR pelos 38 municípios prioritários do Rio Grande do Sul (2007-2011)

\begin{tabular}{|l|c|}
\hline \multicolumn{2}{|c|}{$\begin{array}{c}\text { Gestão democrática: articulação e desenvolvimento } \\
\text { dos sistemas municipais de ensino }\end{array}$} \\
\hline Indicador & $\begin{array}{c}\text { Número de municípios que selecionaram } \\
\text { o indicador para intervenção }\end{array}$ \\
\hline $\begin{array}{l}\text { Existência e funcionamento } \\
\text { de conselhos escolares }\end{array}$ & 34 \\
\hline $\begin{array}{l}\text { Existência, composição e atuação do } \\
\text { Conselho Municipal de Educação }\end{array}$ & 7 \\
\hline $\begin{array}{l}\text { Existência de projeto pedagógico nas } \\
\text { escolas e grau de participação dos } \\
\text { professores, dos conselhos escolares e } \\
\text { orientação da Secretaria Municipal de } \\
\begin{array}{l}\text { Educação considerando as especificidades } \\
\text { da escola na sua elaboração }\end{array}\end{array}$ \\
\hline Critérios para a escolha da direção escolar \\
\hline $\begin{array}{l}\text { Existência, acompanhamento e avaliação do } \\
\text { Plano Municipal de Educação, desenvolvido } \\
\text { com base no Plano Nacional de Educação }\end{array}$ \\
\hline
\end{tabular}

Fonte: baseado em UFRGS (2010).

Elaboração da autora. 
no que diz respeito à criação dos instrumentos e espaços de gestão democrática, bem como sobre a atuação dos atores no âmbito da escola. O Quadro 3 indica as

\section{Quadro 3 - Ação, subações e responsabilidades} de realização do indicador Conselho Escolar

\begin{tabular}{|c|c|c|c|c|c|c|}
\hline & & imensão & - Gestão E & ducacional & & \\
\hline Área gestãc & democrátic & a: articula & çãa e desen & volvimento dos & sistemas & de ensino \\
\hline & Critérios & & & ções proposta & & \\
\hline Indicador & $\begin{array}{c}\text { de } \\
\text { pontuação }\end{array}$ & Ação & Subações & Metodologia & $\begin{array}{r}\text { Ente fe } \\
\text { respo }\end{array}$ & $\begin{array}{l}\text { derativo } \\
\text { nsável }\end{array}$ \\
\hline & & & $\begin{array}{c}\text { Reunir os } \\
\text { segmentos da } \\
\text { comunidade } \\
\text { escolar para } \\
\text { orientar e } \\
\text { incentivar a }\end{array}$ & $\begin{array}{l}\text { Reuniões com } \\
\text { os diversos } \\
\text { segmentos da } \\
\text { comunidade } \\
\text { escolar para } \\
\text { a criacão dos }\end{array}$ & $\begin{array}{c}\text { União } \\
\text { (Ministério } \\
\text { da } \\
\text { Educação) }\end{array}$ & $\begin{array}{l}\text { Prefeitura } \\
\text { Municipal } \\
\text { (Secretaria } \\
\text { Municipal } \\
\quad \text { de } \\
\text { Educação) } \\
\end{array}$ \\
\hline & Quando & & $\begin{array}{c}\text { craçaoo dos } \\
\text { conselhos } \\
\text { escolares }\end{array}$ & $\begin{array}{l}\text { conselhos } \\
\text { escolares }\end{array}$ & & $\mathrm{X}$ \\
\hline & $\begin{array}{c}\text { não existem } \\
\text { conselhos } \\
\text { escolares } \\
\text { implantados: } \\
\text { a Secretaria } \\
\text { Municipal }\end{array}$ & & $\begin{array}{c}\text { Qualificar } \\
\text { técnicos da } \\
\text { Secretaria } \\
\text { Municipal } \\
\text { de Educação } \\
\text { que serão os }\end{array}$ & \begin{tabular}{|c} 
Curso de \\
aperfeiçoamento \\
pelo Programa \\
Nacional de \\
Fortalecimento
\end{tabular} & $\begin{array}{l}\text { União } \\
\text { (Ministério } \\
\quad \text { da } \\
\text { Educação) }\end{array}$ & $\begin{array}{l}\text { Prefeitura } \\
\text { Municipal } \\
\text { (Secretaria } \\
\text { Municipal } \\
\text { de } \\
\text { Educação) }\end{array}$ \\
\hline $\begin{array}{l}\text { Existência e } \\
\text { funcionamento } \\
\text { do conselho }\end{array}$ & \begin{tabular}{|c|} 
de Educação \\
não sugere \\
e tampouco
\end{tabular} & $\begin{array}{l}\text { Implantar } \\
\text { conselhos }\end{array}$ & $\begin{array}{c}\text { multiplicadores } \\
\text { da formação de } \\
\text { conselheiros }\end{array}$ & $\begin{array}{l}\text { dos conselhos } \\
\text { escolares }\end{array}$ & $\mathrm{X}$ & \\
\hline escolar & \begin{tabular}{|c|} 
orienta a \\
implantação. \\
As escolas da \\
rede não se \\
mobilizam \\
para a \\
formação
\end{tabular} & & $\begin{array}{l}\text { Qualificar } \\
\text { conselheiros } \\
\text { escolares }\end{array}$ & $\begin{array}{c}\text { Estudo do } \\
\text { material } \\
\text { instrucional } \\
\text { disponibilizado } \\
\text { pelo Programa } \\
\text { Nacional de }\end{array}$ & $\begin{array}{c}\text { União } \\
\text { (Ministério } \\
\text { da } \\
\text { Educação) }\end{array}$ & $\begin{array}{l}\text { Prefeitura } \\
\text { Municipal } \\
\text { (Secretaria } \\
\text { Municipal } \\
\quad \text { de } \\
\text { Educação) } \\
\end{array}$ \\
\hline & $\begin{array}{c}\text { do conselho } \\
\text { escolar }\end{array}$ & & & $\begin{array}{c}\text { Fortalecimento } \\
\text { de conselhos } \\
\text { escolares }\end{array}$ & & $\mathrm{X}$ \\
\hline & & & $\begin{array}{c}\text { Monitorar a } \\
\text { atuação dos } \\
\text { conselhos } \\
\text { escolares }\end{array}$ & & $\begin{array}{l}\text { União } \\
\text { (Ministério } \\
\text { da } \\
\text { Educação) }\end{array}$ & $\begin{array}{l}\text { Prefeitura } \\
\text { Municipal } \\
\text { (Secretaria } \\
\text { Municipal } \\
\quad \text { de } \\
\text { Educação) } \\
\end{array}$ \\
\hline & & & & & & X \\
\hline
\end{tabular}

Fonte: baseado em Brasil (2007b).

Elaboração da autora. 
ações e subações relativas ao indicador "conselho escolar" e responsabilidades do entes para a sua realização. ${ }^{13}$

Como se pode perceber, todo o processo de construção democrática da gestão da escola é induzida pelo MEC, já que o município não participou da elaboração do texto da política quando ela foi formulada, pois é nesse contexto (da influência) que os conceitos adquirem legitimidade e constituem o discurso de base para a política (Bowe, Ball e Gold,1992). No Quadro 3 tem-se a descrição da escolha do critério 1 (Quadro 1) para o indicador "existência e funcionamento do conselho escolar". No processo de elaboração do PAR nos municípios, esse é o momento do planejamento das ações de intervenção na situação educacional. Todas as subações articuladas, conforme sua metodologia de realização, terão prazo para serem executadas. Observa-se que, entre as quatro subações elencadas, apenas uma delas é de responsabilidade do MEC; todas as outras são de responsabilidade do município. Contudo, as subações estão implicadas entre si, de forma que a ação só se concretiza quando todas as subações forem realizadas pelos entes responsáveis.

O indicador "existência, composição e atuação do Conselho Municipal de Educação" é selecionado para intervenção por 7 (18\%) dos 38 municípios prioritários. Esse indicador representa, no entanto, uma das maiores fontes de tensão no processo de construção da gestão democrática do sistema municipal de ensino, cuja maior característica é o compartilhamento do poder de decisão sobre a educação municipal. Supostamente, quando o município institui o sistema municipal de ensino, o Conselho Municipal de Educação toma as decisões e o Poder Executivo (representado pela Secretaria Municipal de Educação) as executa, fiscalizado pelo Conselho Municipal de Educação. ${ }^{14}$

O fato de o indicador apresentar baixa escolha para intervenção articulada não significa necessariamente que ele esteja em situação satisfatória ou positiva na organização e exercício de suas funções, já que a equipe local dos municípios contava, em sua maior parte, com representantes da Secretaria Municipal de Educação, bem como com os próprio/as secretários/as de educação, e nem sempre com representantes do Conselho Municipal de Educação. Os segmentos que deviam

13 É importante ressaltar que esse é o formato do texto da política (guia prático de ações) para a intervenção nos indicadores de todas as dimensões e áreas do PAR no período 2007-2011. Há um planejamento de realização para todas as subações que percorrem o período de 2007 a 2011. No Quadro 3, apontam-se as ações e subações para a escolha do "critério de pontuação 1" para o indicador "conselho escolar". O critério de pontuação 2, que também gerava intervenção, aponta o seguinte: quando existe conselho escolar em menos de 50\% das escolas, pouco atuantes (apenas no papel). A Secretaria Municipal de Educação sugere a implantação, mas não orienta. As escolas da rede, em parte se mobilizam para implantar conselhos escolares, mas não recebem orientação (Brasil, 2007b).

14 Ressalta-se que, em 2006, o Instituto Brasileiro de Geografia e Estatística (IBGE) apontava que apenas $56,4 \%$ dos municípios brasileiros possuíam sistemas próprios de ensino; o restante estava vinculado à normatização dos sistemas estaduais de ensino (Locatelli, 2011). Quando o sistema municipal de ensino é criado, mesmo que não exista legislação nacional regulando, o Conselho Municipal de Educação é legitimado como órgão normativo do sistema municipal de ensino. 
ter representação na equipe local para a elaboração do PAR eram sugeridos pelo MEC; contudo, ficava a critério da secretaria local a formação efetiva do grupo, dentro das possibilidades do município. Nesse sentido, havia margens para a indução do executivo local à escolha ou não de alguns indicadores, independentemente do recurso que fosse vir do MEC.

A relação entre Poder Executivo (Secretaria Municipal de Educação) local e conselhos municipais de educação é historicamente conflituosa no que diz respeito ao compartilhamento horizontal das decisões para a educação municipal. Essa tensão se vê reforçada a partir da emergência do princípio de gestão democrática do ensino público previsto na Constituição de 1988 e regulamentado na legislação educacional dele advindo. Mesmo que, entre todos os órgãos colegiados presentes nos sistemas e redes municipais de ensino, apenas os conselhos municipais não disponham de norma nacional específica com determinação de criação ou competência (Souza, Duarte e Oliveira, 2013), isso não tem impedido a sua organização e reorganização no âmbito dos municípios, sendo crescentemente legitimados como instrumentos de gestão democrática dos sistemas municipais de ensino com funções normativas, deliberativas e mobilizadoras da sociedade local.

O indicador "existência de projeto pedagógico nas escolas e grau de participação [...]” foi selecionado para intervenção por 24 (63\%) dos 38 municípios prioritários. Esse indicador relaciona-se diretamente com os artigos 14 e 15 da LDBEN n. 9.394/1996 (Brasil, 1996), que preceituam maior participação da comunidade escolar na construção da autonomia da escola pública por meio da participação na gestão pedagógica, administrativa e financeira da unidade escolar. Segundo o artigo 14, "os sistemas de ensino definirão as normas da gestão democrática do ensino público na educação básica, de acordo com suas peculiaridades [...]”, e ainda, no artigo 15, estabelece que "os sistemas de ensino assegurarão às unidades escolares públicas que os integram progressivos graus de autonomia pedagógica e administrativa e de gestão financeira [...]". Porém, o dado aponta para uma situação crítica ou insuficiente do indicador em 63\% dos 38 municípios prioritários analisados (Quadro 2). Nesse sentido, pode-se inferir que, especificamente em relação a esse indicador, o maior responsável por sua concretização é o município, pois a autonomia das escolas é construída pari passu à autonomia que o próprio sistema municipal de ensino lhe assegura.

O que se pode depreender do dado, apontado no Quadro 2, é que provavelmente os municípios elaboram o projeto político-pedagógico sem a participação das escolas e dos professores e profissionais da educação, o que configura uma indução da Secretaria Municipal de Educação para as escolas. Porém, o alto percentual de escolha da equipe local para que haja intervenção nesse indicador aponta certa insatisfação da comunidade escolar, bem como o desejo de participar na construção da gestão democrática da escola. No que tange às ações de intervenção no indicador propostos no "guia prático de ações"(Brasil,2007b), observa-se a mesma indução do processo do MEC para os municípios a partir das subações, com uma metodologia indutiva de práticas, com a maioria prevista para a execução municipal. Chama-se atenção, porém, para o efeito provocado pelo diagnóstico da situação educacional do município conforme o "instrumento de campo"(Brasil,2007a) sobre a emergência de 
uma reflexão que expõe uma tensão e uma disputa no âmbito das municipalidades. Os atores locais não interpretam a política de forma ingênua; eles engendram nessa leitura suas concepções de mundo e de política, considerando suas experiências e vivências do local (Ball, 1994). Os atores locais são sujeitos históricos, ${ }^{15} \mathrm{e}$ é nesse sentido que os efeitos da política podem ser medidos.

O indicador "critério para escolha da direção escolar" é selecionado para intervenção por $23(62 \%)$ dos 38 municípios prioritários. Esse indicador gera tensão tanto no âmbito nacional quanto local. $\mathrm{O}$ próprio MEC exonera-se, no texto da política nacional 2007-2011, de fazer indução para à eleição da direção escolar como critério mais apropriado à construção da gestão democrática da escola; porém, no “instrumento diagnóstico PAR Municipal 2011-2014” (Brasil, 2011), curiosamente esse indicador muda de área: saí da gestão democrática: articulação e desenvolvimentos dos sistemas de ensino e passa para uma nova área, que é criada na segunda edição do PAR; trata-se da área gestão de pessoas.

Contudo, no PAR 2011-2014, o texto da política apresenta para o diagnóstico da situação educacional do município, além das situações dadas pelos critérios de pontuação (Quadro 1 e Quadro 3), os conceitos envolvidos com o indicador, bem como as questões para discussão. Nesse novo conteúdo da política surgem conceitos para discussão do indicador "critérios para a escolha da direção escolar", que supostamente estão relacionados com a gestão democrática, tais como: gestão democrática participativa, autonomia, mobilização da comunidade escolar, democratização, participação, papel do diretor, publicização da gestão pública, base constitucional e normativa para a escolha da direção escolar. O contraditório revela-se na troca de área, pois, ao sair da área que incorpora a gestão democrática como base para o desenvolvimento dos sistemas municipais de ensino, o texto da política nacional parece assumir contornos cuja lógica estaria mais associada a uma racionalidade gerencialista do bem público, ${ }^{16}$ visto que o termo "gestão de pessoas" emerge sob essa lógica sendo frequentemente utilizado pela gestão do setor privado. Já no que

15 Sujeito histórico é aquele que elabora a própria concepção de mundo de maneira crítica e consciente e, portanto, escolhe a própria esfera de atividade, participa ativamente na produção da história do mundo e é o guia de si mesmo, não aceitando do exterior, passiva e servilmente, a marca da própria personalidade (Gramsci, 1986).

16 Perspectiva inerente ao modelo normativo global de gestão pública que implicou a adoção de teorias e técnicas gerenciais próprias do campo da administração de empresas para a gestão da educação, alçando os gestores dos sistemas de ensino e os próprios diretores e professores das unidades escolares ao papel principal de veículo de inserção do novo gerencialismo como modelo de organização e gestão do sistema educacional. Pelo viés do novo gerencialismo, o gestor educacional busca os melhores resultados desenvolvendo competências por meio de uma performatividade que atua como um método de regulamentação, o qual emprega julgamentos, comparações e demonstrações como meio de controle, atrito e mudança. Os desempenhos individuais servem de parâmetro de produtividade ou de resultado, ou ainda como demonstrações de "qualidade" ou "momentos" de promoção ou inspeção (Ball, 2005). No Brasil, a incorporação do novo gerencialismo à gestão pública, além de não romper com os persistentes traços da gestão patrimonialista, passa a constituir-se em modelo concorrente à gestão democrática da educação reivindicada e conquistada pela sociedade civil organizada na década de 1980 . 
se refere à lógica patrimonialista da gestão pública brasileira, a função de diretor/a de escola tem sido, no terreno da política partidária, moeda de troca de cunho clientelista no âmbito dos municípios (Medeiros, 2006), que, sob os auspícios do novo gerencialismo, além de não ser rompida pode ser reforçada.

Por último, o indicador "existência, acompanhamento e avaliação do Plano Municipal de Educação, desenvolvido com base no Plano Nacional de Educação" é selecionado para intervenção por 25 (64\%) dos 38 municípios prioritários. Esse dado aponta que grande parte dos municípios analisados apresenta uma situação crítica ou insuficiente para o indicador Plano Municipal de Educação. A descrição dos critérios de pontuação 1 e 2 para esse indicador aponta para o seguinte:

- critério de pontuação 1: quando não existe nenhuma forma de acompanhamento e avaliação das metas do Plano Municipal de Educação, por parte da Secretaria Municipal de Educação, ou previsão de implantação, ou ainda quando não existe um Plano Municipal de Educação;

- critério de pontuação 2: quando existe um Plano Municipal de Educação e um planejamento para a implementação de programa para o acompanhamento e avaliação de suas metas, mas no planejamento não está prevista a criação de um conselho com participação de professores e gestores e de representantes da sociedade civil organizada (Brasil, 2007b).

Essas são as duas situações, entre quatro, que geravam no PAR 2007-2011 ações de intervenção articulada entre MEC e município.

Neste texto optou-se por não apontar qual foi o critério de pontuação selecionado pelo município para o indicador, ou seja, se foi o critério de pontuação 1 ou o de pontuação 2, uma vez que os dois geravam intervenção articulada. Contudo, no caso específico do indicador Plano Municipal de Educação, pode-se perceber o contraste entre as duas pontuações; no critério de pontuação 1 a intervenção está relacionada diretamente a não existência do Plano Municipal de Educação reforçando a necessidade de sua elaboração e implementação, já o critério de pontuação 2 induz explicitamente à criação de um conselho de acompanhamentodo Plano Municipal de Educação, desconsiderando o papel do próprio Conselho Municipal de Educação para a execução dessa função. Tal desconsideração pode vir a criar ou reforçar os conflitos locais sobre o papel dos conselhos municipais de educação na construção e acompanhamento do Plano Municipal de Educação. Confrontando o percentual de escolha do indicador para a intervenção articulada (64\% dos 38 municípios prioritários) com outro dado retirado do Sistema de Informações sobre os Conselhos Municipais de Educação (SICME), ${ }^{17}$ considerando os 38 municípios prioritários, tem-se a indicação de que 22 municípios (58\%) possuem Plano Municipal de Educação. Isso significa que apenas 3 municípios dos 25 que apontaram o indicador para intervenção não possuem Plano Municipal de Educação. Nesse caso, o critério de pontuação 2, que previa a criação de um conselho de acompanhamento, teve predominância.

17 Disponível em: <http://sicme.mec.gov.br/cte/relatoriopublico/principal.php>. Acesso em: 20 jan. 2010. 
O que se pode destacar do texto da política ("guia prático de ações") para o indicador Plano Municipal de Educação é que para ambos os critérios de pontuação o MEC ofertava como subações articuladas dois cursos de qualificação para a equipe da Secretaria Municipal de Educação excluindo da formação o Conselho Municipal de Educação. Se o texto da política nacional expressa a sua representação como resultado de disputas e acordos, conforme indicam Bowe, Ball e Gold (1992), pode-se inferir que ele reproduz certo descrédito em relação às possibilidades de funcionamento regular dos conselhos municipais de educação, assim como em relação às possibilidades de estarem contribuindo de modo efetivo para o processo de emancipação social e local (Souza e Vasconcelos, 2006).

Ao analisar os indicadores selecionados pelo texto da política nacional PAR, pode-se assinalar a complexa relação entre autonomia dos municípios e a gestão democrática dos sistemas municipais de ensino. Por um lado, o ordenamento constitucional garante a autonomia dos municípios para a organização e gestão da educação municipal indicando para a formulação e implementação de políticas elaboradas localmente, por outro, a União, por meio do MEC, tem como incumbência reconhecida na LDBEN n. 9.394/1996 (Brasil, 1996) a coordenação da política nacional de educação, dotando o governo federal de legitimidade, mesmo que se possa contestar a indução de políticas públicas para os governos subnacionais na formulação e implementação de programas e projetos elaborados no âmbito central, isso tudo mediado pelo regime de colaboração.

Conforme foi possível perceber, os dados apontaram situações em que a implementação do PAR nos municípios tiveram efeitos diversos: gerou autorreflexão local sobre a situação de indicadores da gestão democrática da educação induzindo a práticas democráticas, mas também privou o município de construir autonomamente a democracia local; ainda que se possa argumentar que nem sempre a autonomia está relacionada à democracia, uma vez que os poderes locais têm sido, historicamente, lócus de reprodução da dominação patrimonialista, modelo que contribui para gestões autoritárias do bem público.

\section{CONSIDERAÇÕES FINAIS}

Nestas considerações pretende-se retomar algumas questões pertinentes às argumentações do texto. Primeiramente, retoma-se a noção de "indução" de políticas educacionais a fim de realizar uma breve incursão sobre a relação políticas nacionais e políticas locais (municipais) sob o ponto de vista da abordagem metodológica do ciclo de políticas, externando assim o posicionamento do texto em relação às políticas nacionais. Como se sabe, a etimologia da palavra indução é utilizada em muitas áreas do conhecimento; contudo, aqui se deseja simplesmente a relacionar ao ato de induzimento no sentido de instigar, estimular, convencer.

Dessa forma, a atribuição de coordenação de políticas educacionais nacionais do MEC traz subjacente o papel de indução. Do ponto de vista da abordagem do ciclo de políticas (Ball, 1994; Bowe, Ball e Gold,1992), a relação entre o nacional e o local se dá por meio de contextos inter-relacionados (contexto da influência, contexto do texto, contexto da prática), que podem ocorrer simultaneamente tanto na relação entre 
as políticas nacionais induzidas para o local, quanto na implementação de políticas locais. Isto é, se pensarmos a implementação de políticas públicas como um processo não linear, a possibilidade de imposição de significados para as políticas educacionais oriundas do centro (União/MEC) para o local (municípios) pode ser relativizada, já que os municípios são atores com uma história própria e singular, e a leitura que farão do texto da política estará relacionada com essa singularidade. No contexto da prática, a política passa por uma reinterpretação que, mesmo mantendo as diretrizes da política nacional, pode também induzir a ressignificação da política original.

Outra questão a ser ressaltada refere-se às condições dos municípios para ter acesso aos programas do PAR com vistas à melhoria da qualidade do ensino público municipal, que reporta à adesão voluntária ao plano de metas. Essa adesão pode ser questionada uma vez que os municípios que decidissem não aderir estariam sendo excluídos dos benefícios de recursos técnicos e financeiros de ordem voluntária do MEC. Considerando a precariedade material e técnico-administrativa de muitos municípios brasileiros, a adesão torna-se imposição.

Já o aspecto positivo dessa condição é que aqueles municípios com maior capital político (clientelismo político), que sempre tiveram acesso aos programas voluntários, agora somente o terão por meio de adesão ao PAR; isto é, tais programas constituíam-se em moeda de troca política e privilégio para poucos municípios. Farenzena e Marchand (2013, p. 808) indicam que a inflexão representada pelo Plano de Metas "altera os critérios e procedimentos da assistência voluntária. Portanto, há ruptura da regulação de corte clientelista, com instalação de uma regulação depactuação e contratualização".

Contudo, as mesmas autoras salientam em sua análise que o montante de recursos de assistência voluntária é inexpressivo diante dos objetivos e metas do plano de metas, como também dos compromissos que a União assume com o PAR. Ou seja, considerando a abrangência da política e o número de entes que potencialmente podem receber recursos, assim como o número de matrículas na educação básica, não existe compatibilidade entre o gasto com assistência voluntária e o que é projetado ou prometido pela União ao plano de metas/PAR. Assim, uma política com o escopo de abrangência do PAR sem o devido provimento de recursos para a implementação das ações e subações planejadas tende a perder legitimidade nos municípios.

Finalmente, a análise realizada com base nos dados da implementação do PAR no Rio Grande do Sul demonstra que a relação entre a gestão democrática dos sistemas municipais de ensino e a autonomia dos municípios não é dada a priori. Essa é uma construção social que precisa ser realizada considerando as especificidades socioeconômicas, políticas e culturais das municipalidades.

\section{REFERÊNCIAS}

Abruscio, F. L. Os avanços e os dilemas do modelo pós-burocrático: reforma da administração pública à luz da experiência internacional recente. In: Pereira, L. C. B.; Spink, P. K. (Orgs.). Reforma do Estado e a administração pública gerencial. Rio de Janeiro: FGV, 2006. p. 28-45. 
Afonso, A.J. Reforma do Estado e políticas educacionais: entre a crise do Estado-nação e a emergência da regulação supranacional. Educação E̊ Sociedade, Campinas: CEDES, v. 22 , n. 75 , p. 15-26, ago. 2001.

. Mudanças no Estado-avaliador: comparativismo internacional e teoria da modernização revisitada. Revista Brasileira de Educação, Rio de Janeiro: ANPEd; Campinas: Autores Associados, v. 18, n. 53, p. 267-490, abr./jun. 2013.

Arretche, M. Relações federativas nas políticas sociais. Educação E Sociedade, Campinas: CEDES, v. 23, n. 80, p. 29-40, set. 2002.

Azevedo,J. M. L. Educação como politica pública. Campinas: Autores Associados, 2001. . O Estado, a política educacional e a regulação do setor educação no Brasil: uma abordagem histórica. In: Ferreira, N. S. C.; Aguiar, M. A. S. (Orgs.). Gestão da educação: impasses, perspectivas e compromissos. São Paulo: Cortez, 2004. p. 17-42.

BALL, S. Education reform: a critical and post structural approach. Buckingham: Open University Press, 1994.

. Profissionalismo, gerencialismo e performatividade. Cadernos de Pesquisa, São Paulo: Fundação Carlos Chagas; Campinas: Autores Associados, v. 35, n. 126, p. 539561, set./dez. 2005.

Performatividades e fabricações na economia educacional. Educação छ Realidade, Porto Alegre: UFRGS, v. 35, n. 2, p. 37-56, maio/ago. 2010.

. Novos Estados, nova governança e nova política educacional. In: Apple, M.; Ball, S.; Gandin, L. A. (Orgs.). Sociologia da educação: análise internacional. Porto Alegre: Penso, 2013.

Batista, N. C. Políticas públicas para a gestão democrática da educação básica: um estudo do Programa Nacional de Formação de Conselheiros Municipais de Educação.Jundiaí: Paco Editorial, 2013.

Batista, N. C.; Schuch, C. C. T.; Bürgie, D. B.; Mello, E. M. B.; Medeiros, I. L. P. Análise da implementação do Plano de Ações Articuladas em municípios do Rio Grande do Sul. Série Estudos - Periódico do Programa de Pós-Graduação em Educação da UCDB, Campo Grande: UCDB, n. 34, p. 75-92, jul./dez. 2012.

Borges, A. Ética burocrática, mercado e ideologia administrativa: contradições da resposta conservadora à "crise de caráter" do Estado. Dados, Rio de Janeiro: UERJ, v. 43, n. 1, p. 651-686, 2000.

Bowe, R.; BALL, S.; Gold, A. Reforming education and changing schools: case studies in policy sociology. London: Routledge, 1992.

Brasil. Constituição (1988). Constituição da República Federativa do Brasil. Diário Oficial da União, Brasília, 5 out. 1988.

. Lei n. 9.394, de 20 de dezembro de 1996. Estabelece as Diretrizes e Bases da Educação Nacional. Diário Oficial da União, Brasília, 23 dez. 1996.

. Ministério da Educação. Plano de Metas Compromisso Todos pela Educação: instrumento de campo. Brasília: MEC, 2007a. 
Brasil. Ministério da Educação. Plano de Metas Compromisso Todos pela Educação: guia prático de ações. Brasília: MEC, 2007b.

. Decreto n. 6.094, de 24 de abril de 2007. Dispõe sobre a implementação do Plano de Metas Compromisso Todos pela Educação, pela União Federal, em regime de colaboração com municípios, Distrito Federal e estados, e a participação das famílias e da comunidade, mediante programas e ações de assistência técnica e financeira, visando à mobilização social pela melhoria da qualidade da educação básica. Diário Oficial da União, Brasília, 25 abr. 2007c.

. Ministério da Educação. Fundo Nacional de Desenvolvimento da Educação. Resolução CD/FNDE n. 29, de 20 de junho de 2007. Estabelece os critérios, os parâmetros e os procedimentos para a operacionalização da assistência financeira suplementar a projetos educacionais, no âmbito do Compromisso Todos pela Educação, no exercício de 2007. Diário Oficial da União, Brasília, 29 jun. 2007d.

Ministério da Educação. Plano de Metas Compromisso Todos pela Educação: instrumento diagnóstico PAR Municipal 2011-2014. Brasília: MEC, 2011.

.Lei n. 12.695, de 25 de julho de 2012. Dispõe sobre o apoio técnico ou financeiro da União no âmbito do Plano de Ações Articuladas; altera a lei n.11.947, de 16 de junho de 2009, para incluir os polos presenciais do sistema Universidade Aberta do Brasil na assistência financeira do Programa Dinheiro Direto na Escola; altera a lei n. 11.494, de 20 de junho de 2007, para contemplar com recursos do FUNDEB as instituições comunitárias que atuam na educação do campo; altera a lei n. 10.880, de 9 de junho de 2004, para dispor sobre a assistência financeira da União no âmbito do Programa de Apoio aos Sistemas de Ensino para Atendimento à Educação de Jovens e Adultos; altera a lei n 8.405, de 9 de janeiro de 1992; e dá outras providências. Diário Oficial da União, Brasília, 26 jul. 2012.

Castro, J. A.; Duarte, B. Descentralização da educação pública no Brasil: trajetória dos gastos e das matrículas. Brasília: IPEA, 2008. (Texto para Discussão, 1352).

Coelno, M. I. Vinte anos de avaliação da educação básica no Brasil: aprendizagens e desafios. Ensaio - Avaliação e Políticas Públicas em Educação, Rio de Janeiro: CESGRANRIO, v. 16, n. 59, p. 229-258, abr./jun. 2008.

Farenzena, N. (Org.). Implementação de Planos de Ações Articuladas municipais: uma avaliação em quatro estado brasileiros. Pelotas: UFPEL, 2012.

Farenzena, N.; Marchand, P. Relações intergovernamentais na educação à luz do conceito de regulação. Cadernos de Pesquisa, São Paulo: Fundação Carlos Chagas; Campinas: Autores Associados, v. 43, n. 150, p. 788-808, set./dez. 2013.

FÉLIx, L . Coronelismo, borgismo e cooptação política. Porto Alegre: Mercado Aberto, 1987. GiL, A. C. Métodos e técnicas de pesquisa. São Paulo: Atlas, 1994.

Gramsci, A. Concep̧̧ão dialética da história. 6. ed. Rio de Janeiro: Civilização Brasileira, 1986.

Locatelli, C. A política de descentralização na educação brasileira: resultados e consequências. In: Jornada Internacional de Políticas Públicas, 5., 2011, São Luis do Maranhão. Anais... São Luis do Maranhão: UFMA, 2011. 
Luce, M. B.; Farenzena, N. Conselhos Municipais de Educação, descentralização e gestão democrática: discutindo interseções. In: SouzA, D. B. (Org.). Conselhos municipais e controle social da educação: descentralização, participação e cidadania. São Paulo: Xamã, 2008. p. 75-96.

Medeiros, I. L. Gestão democrática e escolha do diretor de escola. In: Luce, M. B.; Medeiros, I. L. (Orgs.). Gestão escolar democrática: concepções e vivências. Porto Alegre: Editora UFRGS, 2006. p. 51-66.

Müller, P.; Surel, Y. A análise de políticas públicas. Pelotas: Educat, 2002. (Coleção Desenvolvimento Social).

Nogueira, M. A. Um Estado para a sociedade civil: temas éticos e políticas da gestão democrática. São Paulo: Cortez, 2004.

SAviani, D. Sistemas de ensino e planos de educação: o âmbito dos municípios. Educação E Sociedade, Campinas: CEDES, ano XX, n. 69, p. 119-136, dez. 1999.

Souza, D. B.; Duarte, M. R. T.; Oliveira, R. F. CMEs no Brasil: uma cartografia a partir dos estudos teórico-empíricos. In: Souza, D. B. (Org.). Mapa dos conselhos municipais de educação no Brasil: criação, implantação e funcionamento institucional e sociopolítico. São Paulo: Edições Loyola, 2013. p. 23-55.

Souza, D. B.; Vasconcelos, M. C. C. Os conselhos municipais de educação no Brasil: um balanço das referências nacionais (1996-2002). Ensaio-Avaliação e Políticas Públicas em Educaşão, Rio de Janeiro: CESGRANRIO, v. 14, n. 50, p. 39-56, mar. 2006.

Souza, D. B.; Batista, N. C. Balanço das avaliações municipais do plano de ações articuladas: desafios atuais ao desenvolvimento da política nacional PAR. Educação em Revista, Belo Horizonte: UFMG, v. 32, n. 1, p. 105-131, jan./mar. 2016.

UFRGS - Universidade Federal do Rio Grande do Sul. Faculdade de Educação. Núcleo de Estudos de Políticas e Gestão da Educação. Banco de dados de 38 municípios prioritários que implementaram o PAR no RS. Porto Alegre: FACED; NEPGE, 2010.

\section{SOBRE A AUTORA}

Neusa Chaves Batista é doutora em educação pela Universidade Federal do Rio Grande do Sul (UFRGS). Professora da mesma instituição. E-mail: neuchaves@gmail.com

Recebido em 5 de agosto de 2015 Aprovado em 9 de maio de 2016 